\title{
Participação, cidadania e ciberdemocracia no Brasil
}

\section{Arthur Ituassu}

\section{Resenha}

MAIA, Rousiley Celi Moreira; GOMES, Wilson;

MARQUES, Francisco Paulo Jamil Almeida (Org.).

Internet e participação política no Brasil. Porto

Alegre: Editora Meridional; Sulina, 2011.
Arthur Ituassu | ituassu@puc-rio.br

Professor do Departamento de Comunicação Social da Pontifícia Universidade Católica do Rio de Janeiro (PUC-Rio).

\section{Introdução}

As implicações que a comunicação via internet traz e pode trazer para o mundo da política ou mais especificamente para a democracia já se configuram como um tema consolidado na área da Comunicação Social, em especial no campo de Comunicação e Política. Para além dos artigos acadêmicos, a questão está presente há algum tempo nas obras e coletâneas da área (BENNETT; ENTMAN, 2001; GOMES, 2004; GOMES; MAIA, 2008; MIGUEL; BIROLI, 2010). No entanto, mais recentemente, começou a ser tratada em obras dedicadas exclusivamente ao tema (CHADWICK; HOWARD, 2009; COLEMAN; BLUMER, 2009).

Internet e participação política no Brasil

foi organizado pelos professores Rousiley Celi Moreira Maia, associada do Departamento de Comunicação Social da Universidade Federal de Minas Gerais (UFMG); Wilson Gomes, titular na Faculdade de Comunicação da Universidade Federal da Bahia (UFBA); e Francisco Paulo Jamil Almeida Marques, ex-pesquisador da UFBA e hoje efetivo na Universidade Federal do Ceará. Como dizem os organizadores, o livro vem preencher 
"uma lacuna" dessa literatura no Brasil. Afinal, "ainda são poucas" as produções brasileiras que abordem, de modo sistemático, os impactos que as diferentes inovações introduzidas pela internet provocam nos fenômenos gerados pela "influência da comunicação de massa sobre as práticas políticas" no país (p. 11).

Nesse sentido, o livro tem como princípio norteador examinar "as atribuições participativas que Estado e sociedade conferem à internet" (p. 11) e os "usos políticos dos new media voltados para fortalecer a participação dos cidadãos", tomados "tanto em suas manifestações institucionais-estatais quanto naquelas oriundas da sociedade civil" (p. 12).

A obra é dividida em três partes. Na primeira, "Participação política e internet: conceitos fundamentais", está a teoria do trabalho. 0s textos Participação política online: questões e hipóteses de trabalho, de Wilson Gomes, e Internet e esfera civil: limites e alcances da participação política, de Rousiley Maia, estabelecem o contexto teórico que embasa, inclusive, a cooperação acadêmica apoiada pela Capes - entre 0 Grupo de Pesquisa em Comunicação, Internet e Democracia (UFBA), coordenado pelo professor Gomes, e 0 Grupo de Pesquisa em Mídia e Esfera Pública (EME/UFMG), dirigido pela professora Maia.

Estabelecer o marco teórico, que inclua a teoria política e a teoria da democracia, é fundamental a qualquer trabalho desse tipo. Gomes aborda esse ponto mais claramente em outra ocasião, quando afirmou que "todo desenho de governo eletrônico, cidade digital, inciativa pró-democracia do Estado ou da sociedade civil é sustentado por um modelo de democracia" (GOMES, 2010, p. 253). Para se estudar Comunicação e Política, como disciplina, é preciso dialogar as teorias dos dois campos. Isso implica que qualquer incursão na área, de caráter mais analítico ou normativo, deve ter transparente a teoria política que trabalha como referência. No caso específico da democracia, deve estabelecer um posicionamento claro e obrigatório acerca dos debates relativos à teoria do tema.

Com tal requisito em mente, percebe-se que 0 posicionamento teórico da parceria entre os pesquisadores da UFBA e da UFMG está até mais detalhadamente apresentado e desenvolvido em outro trabalho da dupla Gomes e Maia: Comunicação e democracia, que, antes de incluir 0 ambiente virtual como campo de pesquisa, analisa as relações "entre a comunicação de massa e os processos políticos democráticos" (GOMES; MAIA, 2008, p. 11). Na obra, os autores chamam a atenção, entre outros pontos, para 0 fato de que 0 tratamento habitual do tema "comunicação e democracia" acaba muitas vezes por gerar uma "abordagem pouco cuidadosa no que se refere ao segundo termo da relação" (GOMES; MAIA, 2008, p. 12).

\section{A teoria}

Como afirmam Gomes e Maia, "há praticamente um modelo ou, no mínimo, uma versão de democracia para cada filosofia política digna deste 
nome” (GOMES; MAIA, 2008,, p. 13). Em torno das discussões acerca da "crise da democracia liberal", por exemplo, que envolve temas como a apatia dos eleitores, ausência de efetividade da cidadania, desinteresse público na vida política, informação política distorcida e excessivamente dependente dos meios de massa, baixo capital político da esfera civil, desconexão entre sociedade política e esfera civil, ausência do sentido de soberania popular e desconfiança generalizada com respeito à política (GOMES, 2008), há, atualmente, pelo menos três grandes tradições na mesa: a liberal, a republicana e a deliberativa. "Cada uma dessas linhas de força traz consigo o seu específico patrimônio de questões e de pressupostos e a sua própria agenda" (GOMES; MAIA, 2008, p. 13).

Nesse sentido, o termo "participação", em Internet e participação política no Brasil, ganha um sentido fundamental, ligado ao entendimento da obra e da tradição teórica em que está inserida. Afinal, como deixam mais claro em Comunicação e democracia, Gomes e Maia $(2008$, p. 20) tratam principalmente daqueles problemas "que emergem das perspectivas republicana e deliberacionista, que constituem a inflexão mais à esquerda na tríade dos principais paradigmas contemporâneos da teoria democrática".

Com olhos republicanos, a preocupação está em torno da cidadania, "a inscrição fundamental na comunidade política" (2008, p. 14). Por esse viés, a intenção maior é fazer com que a dimensão civil da sociedade recupere e assegure 0 controle sobre o Estado, entendido como res publica. 0 republicanismo se preocupa com os direitos igualitários e as oportunidades concretas de participação política e de engajamento na vida coletiva por parte da esfera civil (GOMES; MAIA, 2008, p. 14).

Nesse sentido, análises relacionadas à comunicação e democracia se preocupam com 0 favorecimento ou o impedimento à participação gerado "pelas instituições, linguagens e meios de comunicação de massa" (GOMES; MAIA, 2008, p. 14). Além disso, colocam questões à comunidade, entendida como sistema compartilhado de atitudes, valores e representações, tentando perceber se a cultura em questão favorece ou prejudica o engajamento dos cidadãos na formulação e resolução de problemas da comunidade política.

Pelo viés republicano, debates surgem em torno dos mecanismos e das oportunidades de participação política. Há problemas quando a comunicação de massa não cumpre seu dever de formar e reforçar o civismo e favorecer a participação. Nesse contexto, como mostram os autores, 0 rol das questões é amplo e inclui 0 papel do entretenimento de massa na competição pelo tempo livre do cidadão, que poderia ser destinado à participação e ao engajamento, 0 déficit de informação política qualificada em toda a esfera midiática e a indução, por meio de uma cobertura cínica das atividades políticas (CAPELLA; JAMIESON, 1997; ITUASSU, 2011), 
de representações que podem levar à apatia $\mathrm{e}$ ao desengajamento. Nesse contexto, um tipo de "ciberrepublicanismo" promete um mundo novo de participação e comunicação política na rede virtual sem mediação (GOMES; MAIA, 2008, p. 15).

No que diz respeito ao deliberacionismo, um modelo de democracia centrado na questão discursiva, 0 foco de atenção é a materialização de uma arena que funcione como esfera intermediária entre o Estado e a sociedade, como concretização do pressuposto de que os cidadãos devem ter "a capacidade e a oportunidade de deliberar racional e publicamente sobre as decisões coletivas que os afetam e importam" (GOMES; MAIA, 2008, p. 16). Trata-se aqui, como resumem os autores, de ressaltar a importância da "práxis coletiva da troca pública de argumentos" (GOMES; MAIA, 2008, p. 16). Por esse viés, devem ser considerados os fluxos de comunicação presentes nas arenas públicas, onde problemas comuns e questões do Estado e da República são formulados, discutidos, enunciados e examinados (p. 17). A esfera pública política:

[C]ondição social básica para a formação de uma opinião pública política formulada coletivamente e testada por meio de procedimentos argumentativos abertos, que refletem os interesses e preferências representados no corpo da sociedade (GOMES; MAIA, 2008, p. 17).

Independentemente do debate interno ao deliberacionismo, os meios de comunicação de massa nesse contexto têm "uma dupla tarefa e uma dupla agenda": como ambiente de oportunidades para a existência de uma esfera pública qualificada e como conjunto de instrumentos para que a esfera pública se faça valer nas esferas da decisão política (GOMES; MAIA, 2008; BENNETT; ENTMAN, 2001). Nesse contexto, têm recebido particular atenção crítica a qualidade dos argumentos mediados pela comunicação de massa e a representatividade das posições no debate público midiático (GOMES; MAIA, 2008, p. 19). Não à toa, a internet e os novos meios de comunicação são vistos como facilitadores de uma interação direta entre cidadãos e entre cidadãos e uma classe política mais próxima. Não só isso, possibilitam também uma produção argumentativa mais plural da esfera civil, uma comunicação mais aberta a interesses minoritários.

0 conceito de "participação", assim, atua como elo entre as perspectivas deliberacionista e republicana e é inserido na discussão política sobre a internet a partir do potencial que a rede traz de revigorar a cidadania e a esfera da discussão pública, superando alguns déficits da democracia contemporânea, em especial aqueles produzidos e alimentados pela tradicional estrutura de comunicação de massa (GOMES, 2008, p. 303). É para esse sentido que aponta o primeiro texto de Internet e participação política no Brasil, de autoria de Wilson Gomes: Participação política online: questões e hipóteses de trabalho. Nesse contexto teórico, o autor sugere que, embora os modelos de democracia direta tenham se revelado insustentáveis em face do padrão dominante da representação, a 
participação política da esfera civil tem lugar central na arena da teoria contemporânea da democracia.

[J]á que as comunicações digitais em rede representam um conjunto novo de ferramentas para 0 estabelecimento e a extensão das redes sociais, para produzir novas formas de colaboração, informação e interesse político, por que não imaginar que talvez se possa encontrar aqui alguma alternativa de incremento de participação política e engajamento cívico? (p. 20).

Dessa forma, a internet é percebida como um ambiente de comunicação com potencial de transformar o padrão atual de baixa participação política por parte da esfera civil nas democracias contemporâneas. 0 caminho proposto, assim, está sustentado por um conceito específico de democracia digital, que ocorre quando o emprego de dispositivos, aplicativos e ferramentas digitais suplementam, reforçam ou corrigem determinados aspectos da democracia. No contexto teórico estabelecido, tais iniciativas têm a missão de garantir e incrementar a participação nas esferas de decisão, o pluralismo da fala política, as liberdades de expressão, opinião e participação, as oportunidades de controle civil dos tomadores de decisão, a transparência pública e também as experiências de democracia direta.

Para 0 autor, iniciativas digitais que possam incrementar o ambiente democrático devem contemplar pelo menos um dos três prerrequisitos: 1) 0 fortalecimento da cidadania, no sentido de capacitá-la a concorrer com outros interesses no sistema político, interesses econômicos e dos movimentos políticos organizados, por exemplo; 2) o reforço de uma sociedade calcada nos direitos; e 3) a garantia de participação das minorias, ou seja, o pluralismo, a promoção da diversidade de agentes, agências e agendas na esfera pública e nas instâncias de decisão política, potencializando instrumentos, meios e oportunidades para a representação e a participação plural

Dessa forma, no que diz respeito à teoria da democracia, o posicionamento estabelecido ressalta iniciativas no ambiente digital voltadas para "descolonizar o espaço da cidadania", contribuindo para "recompor padrões adequados de soberania popular" (p. 35), sem que, com isso, o conceito de participação esteja necessariamente ligado à democracia direta ou à necessidade de participação massiva.

Se, quando assim o deseja, o cidadão puder encontrar ou criar canais adequados de participação, estará, então, assegurado 0 princípio segundo o qual, numa sociedade democraticamente saudável, todo concernido deve poder participar, embora nem todos os concernidos sejam sempre e efetivamente participantes (p. 39-40).

Nesse sentido, como bem levanta Maia no segundo capítulo mais teórico da obra, Internet e esfera civil: limites e alcances da participação política, a nova infraestrutura virtual, mais rápida e barata, com grande potencial para produção autônoma de informação e com uma variedade de recursos para a conexão e ação política em escala local, nacional e transnacional, traz uma renovação fundamental das atenções sobre 0 alcance e a 
eficácia da atuação política da sociedade civil, entendida como o conjunto de associações, grupos formais ou informais, redes que existem fora da família, das relações íntimas e do Estado e de suas instituições, como o Exército, os partidos, o parlamento ou a burocracia. No entanto, como afirma a autora, não se deve conceber a sociedade civil como "uma esfera autônoma de atividade democrática". 0 simples entendimento da sociedade civil como uma rede de associação à parte do Estado e do mercado "não é suficiente para produzir distinções qualitativas importantes" (p. 56) e a combinação entre os dois níveis de participação - individual e coletivo - parece ser mais apropriada à constituição do ambiente democrático (p. 61).

Aqui, com base em Putnam (1995), Maia afirma que 0 debate recai sobre 0 conceito de "capital social", entendido como relações de proximidade sustentadas por indivíduos que compartilham opiniões, valores e objetivos que possibilitam a construção de redes e a colaboração recíproca. Ou definido como o conjunto de recursos ligados a uma rede durável de relações mais ou menos institucionalizadas, constituídas por trocas materiais e simbólicas cuja instauração e perpetuação supõem o mútuo reconhecimento, diz a autora apoiada em Bourdieu (1998).

Em meio ao debate se a internet reforçaria o "capital social" e o compromisso com as comunidades ou proporcionaria efeito contrário, Maia chama a atenção para o fato de que a maior parte dos autores tem concordado que não é possível derivar efeitos singulares da comunicação digital. Ou seja, a literatura hoje, em geral, concorda que o uso da internet não é uma atividade uniforme, que produz resultados programados e passíveis de serem previstos.

Em um momento em que as formas tradicionais de engajamento cívico estão entrando em declínio e novas formas de participação e novos desenhos institucionais vêm sendo construídos para incrementar a participação política, ferramentas conceituais tradicionais se mostram precárias para abordar essas tendências (p.72-73).

Assim, Maia questiona por exemplo: como a internet interfere nas dinâmicas organizacionais das associações e nos padrões de relação entre ativistas, oponentes e público? Que efeitos sobre as redes são ligados à comunicação digital? Como as redes de ativismo online modificam o jogo político?

Dessa forma, ao levar em conta as características das redes digitais, bem como seus métodos de participação e organização política, a comunicação digital tem, segundo Maia: 1) criado facilidades para a sustentação de campanhas permanentes que têm por objetivo a transformação no modo de entendimento e tratamento de certos problemas, e não, vale dizer, a conquista de uma meta política específica; 2) proporcionado o fortalecimento de redes de protesto em escala global, com uma ampla gama de atividades com graus diferenciados de duração e eficácia; e 3) ajudado na sustentação e disseminação de formas midiáticas táticas e discursos alternativos na esfera pública, que 
podem representar vozes marginalizadas, sustentar contra-discursos, produzir enquadramentos alternativos àqueles convencionais, servir de fontes para jornalistas e agendar temas nas grandes organizações midiáticas.

Se redes virtuais podem sofrer com ausência de direção interna e dificuldades para a produção de decisão coletiva legítima, falta de clareza na definição de conteúdos e enquadramentos compartilhados, bem como com o descontrole sobre a mensagem de suas campanhas, podem também sustentar possibilidades criativas para a ação, inovações sociais e políticas aos modelos tradicionais de participação e representação, em crise na maior parte das democracias ocidentais contemporâneas.

\section{A empiria}

Em seguida à delimitação teórica mais formal, os capítulos seguintes procuram apresentar análises empíricas de certos processos de comunicação política na rede, a partir das questões levantadas em torno das perspectivas republicana $\mathrm{e}$ deliberacionista da teoria democrática. 0 primeiro deles, de Francisco Paulo Jamil Almeida Marques, examina o Portal da Câmara dos Deputados e o Portal da Presidência da República e suas ferramentas como canais de troca de e-mail, formulários, espaços para comentário, enquetes, salas de bate-papo, fóruns públicos etc.

Os objetivos do trabalho, inseridos no escopo teórico mais amplo, são: identificar e sistematizar as oportunidades de participação ofertadas; avaliar 0 grau de aproveitamento dos instrumentos disponibilizados; e apontar indícios sobre a disposição da representação política e das próprias instituições em tornar suas estruturas mais abertas à intervenção e controle públicos. No texto, um resumo da tese de doutoramento do autor, Marques apresenta sua metodologia: análise de documentos oficiais e diretrizes que guiaram a produção dos dois portais; entrevistas com os realizadores, acesso monitorado aos portais entre setembro e abril de 2008; e avaliação qualitativa das ferramentas disponibilizadas.

As considerações finais do autor chamam a atenção para 0 fato de que 0 grau de sofisticação das ferramentas disponíveis não é suficiente para se compreender a natureza da participação política na internet e seus efeitos. É preciso levar em conta a (cultura de) resistência institucional à integração cidadã, ou seja, às dificuldades de cultura política impostas a uma perspectiva de soberania popular mais forte.

Mesmo em experiências nas quais se percebe uma maior provisão de canais participativos, são de se questionar, por exemplo, os efeitos políticos que tais recursos podem gerar, uma vez que não adianta dar voz e oportunidades de expressão e discussão aos usuários se a eles não se demonstra, também, seriedade na consideração das contribuições encaminhadas (p. 116).

A questão também é tratada no texto Exigências democráticas e dimensões analíticas do Estado, capítulo 4 de Internet e participação política no Brasil, onde Sivaldo Pereira da Silva sugere 
"três requisitos democráticos a serem cumpridos pela interface digital do Estado", um dos campos mais férteis de pesquisa envolvendo internet $\mathrm{e}$ política. Segundo o autor, é preciso avaliar se a iniciativa: 1) torna 0 Estado mais transparente ao cidadão, o critério da publicidade; 2) torna 0 Estado mais dialógico com o cidadão, o critério da responsividade; e 3) torna o Estado mais aberto à opinião pública, o critério da porosidade. Para Silva (p. 125), é possível pensar nesses três requisitos democráticos como "um tripé sobre 0 qual os sites do Estado devem se apoiar". Nesse sentido, um portal governamental cumprirá seu papel no incremento do regime democrático não apenas quando dispõe de conteúdo a ponto de prover mais transparência às suas atividades, mas também quando apresenta canais de diálogo com (e entre) 0 cidadão e propicia formas de incorporar a participação on-line nos processos de decisão política.

Além disso, é preciso analisar qualitativamente os processos comunicacionais. Afinal, há diferentes formas de materialização dos requisitos, ou seja, tipos de relações comunicativas (mais densas ou menos densas) que podem ser estabelecidas no ambiente digital. Silva sugere cinco níveis qualitativos. As relações entre 0 Estado e 0 cidadão no ambiente digital podem se dar de modo "utilitário", "informativo", "instrutivo", "argumentativo" ou "decisório". Os quatro primeiros tipos valem para a avaliação da comunicação nos três requisitos, o último, 0 decisório, apenas para o quesito porosidade. 0 autor espera, com isso, "avançar ao estabelecer princípios a serem cumpridos pelos portais governamentais, sem perder de vista uma tipificação quanto às diferentes formas de materializá-los" (p. 140).

0 estudo seguinte, Iniciativas institucionais de deliberação online, de Edna Miola, faz uma análise da participação em um fórum virtual específico posto em prática no Portal da Câmara dos Deputados: 0 fórum da Comissão de Legislação Participativa (CLP). A autora se propõe a analisar o fórum quanto ao tema debatido, utilização e desenho da ferramenta e à motivação fornecida para 0 engajamento cidadão. Além disso, sempre em diálogo com a teoria deliberativa, avaliou também as mensagens qualitativamente quanto à pertinência, ao tom, ao diálogo estabelecido, ao grau de consideração que os debatedores deram aos argumentos alheios em suas intervenções, à reciprocidade ou à ocorrência de manifestações que revelam persuasão, progresso (aspectos positivos para a deliberação) ou radicalização (aspecto negativo), aos "indícios de argumentação racional" nas mensagens e quanto ao uso dos recursos argumentativos de validação externa, interna ou alegação (p. 166-167).

0 fórum da CLP se desenvolveu entre 27 de abril e 19 de outubro de 2005 e reuniu 90 mensagens de 56 participantes em torno da pergunta: "Como a Câmara dos Deputados pode aproximar você, cidadão, e a sociedade civil organizada da Comissão de Legislação Participativa?" 
A análise apresenta dados que mostram a pertinência de boa parte das mensagens trocadas (99\%), o tom respeitoso também da maioria delas (89\%), uma função dialógica relativa - 34\% das mensagens iniciam um debate e $42 \%$ respondem -, uma certa reciprocidade positiva à discussão (64\%) e baixos índices de validação externa (26\%) e interna (34\%), em relação às alegações (39\%).

No entanto, mais do que concluir se a deliberação ocorreu ou não, o intuito, segundo a autora, foi apontar para certos preceitos que podem ser levados em consideração pelas instituições públicas na construção de ferramentas semelhantes. Por exemplo, a importância de se informar 0 cidadão das intenções do fórum. Afinal, o fórum tem a finalidade de influenciar alguma decisão? De que maneira? Outro ponto levantado é a relevância de se proporcionar mecanismos que propiciem a reciprocidade e ampla informação e de fácil acesso sobre 0 tema, até mesmo no sentido de tentar equalizar ao máximo o posicionamento na deliberação. Além disso, a necessidade de se refletir sobre o estímulo a ser fornecido ao cidadão, se apenas de consulta, por exemplo, ou de argumentação e deliberação.

Já a preocupação de Camilo de Oliveira Aggio, no capítulo seguinte, são as campanhas eleitorais via internet. Vale ressaltar, tal campo também fértil da Comunicação e Política não se limita aos usos da rede e seus resultados numa campanha, inclui também as possibilidades de democratização das campanhas, por meio de maior mobilização, participação, engajamento, ou seja, o ativismo online (AGGIO, 2011; MARQUES; SAMPAIO, 2011).

Segundo o autor, há quatro questões fundamentais nos estudos de campanhas on-line. A primeira trata do impacto, na disputa eleitoral, dos novos canais de informação abertos na internet, em especial aqueles não mediados pelas grandes empresas de mídia e jornalismo. A segunda refere-se à queda dos custos de comunicação das campanhas, o que pode alterar positivamente a paridade da disputa. A terceira e a quarta analisam os efeitos de uma comunicação mais direta entre cidadãos e também entre cidadãos e membros de campanhas políticas, seja na produção e organização de atividades em prol de uma candidatura, seja possibilitando 0 exercício do debate, com o objetivo de "promover esclarecimentos ou produção colaborativa de agendas, propostas e diretrizes" (p. 179).

A análise de Camilo Aggio segue a teoria da democracia anteriormente estabelecida e chama a atenção para a possibilidade de ampliação da cidadania nas campanhas, para além do voto, ou seja, nas práticas da dimensão eleitoral. Além disso, 0 autor ainda ressalta a possibilidade, com a ampliação da participação, de um maior contato de cidadãos com candidatos, partidos e equipes de campanha, aproximando o cidadão do sistema político (p. 190).

0 trabalho seguinte, de Rafael Cardoso Sampaio, leva 0 deliberacionismo aos fóruns virtuais de debate. Como o autor mesmo afirma, 0 
crescimento do uso da internet e da utilização de ferramentas que propiciam a interação entre indivíduos - fóruns on-line, sites de redes sociais e outros aparatos semelhantes - fez com que muitos deliberacionistas passassem a ver a rede como um caminho potencial para uma democracia que valorize mais a deliberação entre os cidadãos.

Assim, 0 autor apresenta um modelo específico de avaliação da deliberação e 0 incide sobre os debates em torno do Orçamento Participativo de Belo Horizonte, em 2006 e 2008. A experiência possibilita não tanto avaliar a deliberação ali ocorrida como cruzar os dados estruturais do fórum on-line com os índices de deliberatividade, verificando os pontos fracos e fortes da discussão e das próprias ferramentas digitais.

De modo semelhante, em torno de processos políticos que podem ocorrer no mundo das mídias sociais, Regiane Lucas de Oliveira Garcêz analisa um debate ocorrido na rede social Orkut em torno do reconhecimento dos surdos. 0 pressuposto é 0 de que a internet oferece ferramentas e subsídios para a comunicação que podem ser amplamente utilizados pelos cidadãos, e de modo particular pelos surdos, para diversos fins políticos. Afinal, como diz a autora, para a maioria dos surdos, a internet talvez seja 0 único meio de expressão em que os sujeitos são produtores e veiculadores de suas próprias mensagens, sem a necessidade de intermediários.

Da análise, a autora pôde concluir que testemunhos presentes nas conversações políticas em lutas por reconhecimento podem revelar novas premissas, gerar aprendizado coletivo sobre os modos de vida daqueles que buscam o reconhecimento, chamar a atenção para perspectivas de vida semelhantes, complementar argumentos, configurar sentidos compartilhados, bem como "abrir espaço para o dissenso e 0 desrespeito daqueles que não concordam ou não toleram diferentes perspectivas" (p. 233).

Finalmente, no último estudo da obra, Diógenes Lycarião ressalta 0 fato de que, diante das dificuldades de acesso à esfera da visibilidade pública controladas pelos grandes veículos de mídia, muitos pesquisadores passaram a nutrir a expectativa de que a internet se apresentaria como um meio alternativo à comunicação de massa tradicional. No entanto, afirma 0 autor, assim 0 seria mais no sentido de complementar do que de substituir. É na articulação entre a visibilidade política da comunicação de massa e a argumentação pública apresentada nas ferramentas institucionais presentes no meio virtual que se encontraria "um dos caminhos mais oportunos para se avaliar a ampliação do sistema informativo moderno" (p. 258).

Em meio ao debate, Lycarião faz uma análise da estratégia de comunicação da organização Greenpeace, para gerar visibilidade e discutibilidade acerca dos problemas ambientais. Segundo o autor, ações estético-expressivas espetaculares do Greenpeace são na maior parte das vezes acompanhadas de argumentações que produzem posicionamento político justificado. 
As ferramentas digitais, conclui a pesquisa, exercem papel fundamental nessa divulgação da racionalidade implícita ao movimento.

\section{Considerações finais}

Dessa forma, não há dúvidas de que Internet e participação política cumpre com louvor seus objetivos e abre o debate literário no Brasil sobre o tema, que tende apenas a crescer. No entanto, é importante ter em mente que a obra assim o faz a partir de um posicionamento teórico específico, o que possibilita discussões tanto em torno do paradigma republicanista-deliberacionista assumido pelos autores e organizadores, como também entre teorias.

Afinal, da mesma forma que o republicanismo pode ser associado ao deliberacionismo em uma série de interesses afins, também pode ser apresentado ao lado do liberalismo, em especial na questão comum em torno da igualdade de oportunidades. Tal dimensão no terreno da comunicação, por exemplo, pode ressaltar temas importantes no que diz respeito ao debate político, à esfera pública política no Brasil.

Em um ambiente tradicionalmente concentrado de comunicação, como o brasileiro, sem dúvida há muito terreno a ser explorado com relação à pluralidade que a internet possibilita e os impactos políticos que tal diversidade poderia gerar. Um fenômeno relativamente novo da comunicação que, no Brasil, arrisca este autor, poderia incluir até mesmo a produção de novos significados para a política.

\section{Referências}

AGGIO, C. Campanhas online e participação: Um esforço preliminar de análise da atuação dos eleitores e dos agentes de campanha no projeto Proposta Serra. In: ENCONTRO ANUAL DA COMPÓS, 20., 2011. Porto Alegre. Anais...Brasília: Compós, 2011.

\section{BENNETT, W. L.; ENTMAN, R. M. Mediated}

Politics: communication in the future of democracy. Cambridge: Cambridge University Press, 2001.

BOURDIEU, P. Escritos de educação. Petrópolis, RJ: Vozes, 1998.

CAPELLA, J. N.; JAMIESON, K. H. Spiral of Cynicism: The press and the public good. Oxford: Oxford University Press, 1997.

CHADWICK, A.; HOWARD, P. N. Routledge handbook of internet politics. Nova York: Routledge, 2009.

COLEMAN, S.; BLUMER, J. G. The Internet and Democratic Citizenship: Theory, Practice and Policy. Cambridge: Cambridge University Press, 2009.

GOMES, W. Transformações da política na era da comunicação de massa. São Paulo: Paulus, 2004. . Internet e participação política. In: GOMES, W.; MAIA, R. C. M. Comunicação e democracia. Porto Alegre: Meridional; Sulina, 2008. p. 293-324. 
. Democracia digital: que

democracia? In: MIGUEL, L. F.; BIROLI, F. Mídia,

representação e democracia. São Paulo:

Hucitec, 2010. p. 241-259.

GOMES, W.; MAIA, R. C. M. Comunicação e

democracia. Porto Alegre: Meridional; Sulina, 2008.

ITUASSU, A. 0 enquadramento (ou o preconceito) da descrença. In: ENCONTRO ANUAL DA

COMPÓS, 20., 2011. Porto Alegre. Anais... Brasília:

Compós, 2011.

MARQUES, F. P. J. A.; SAMPAIO, R. C. Election after election: rupturas e continuidades nos padrões midiáticos das campanhas políticas online. In:

ENCONTRO ANUAL DA COMPÓS, 20., 2011. Porto

Alegre. Anais... Brasília: Compós, 2011.

MIGUEL, L. F; BIROLI, F. Mídia, representação

e democracia. São Paulo; Hucitec, 2010.

PUTNAM, R. D. Bowling alone: America's

declining social capital. Journal of Democracy, v.

6, n. 1, p. 65-78, 1995. 


\section{Expediente}

A revista E-Compós é a publicação científica em formato eletrônico da Associação Nacional dos Programas de Pós-Graduação em Comunicação (Compós). Lançada em 2004, tem como principal finalidade difundir a produção acadêmica de pesquisadores da área de Comunicação, inseridos em instituições do Brasil e do exterior.
E-COMPÓS I www.e-compos.org.br I E-ISSN 1808-2599

Revista da Associação Nacional dos Programas de Pós-Graduação em Comunicação.

Brasília, v.14, n.2, maio/ago. 2011.

A identificação das edições, a partir de 2008 passa a ser volume anual com três números.

\section{CONSELHO EDITORIAL}

Afonso Albuquerque, Universidade Federal Fluminense, Brasil Alberto Carlos Augusto Klein, Universidade Estadual de Londrina, Brasil Alex Fernando Teixeira Primo, Universidade Federal do Rio Grande do Sul, Brasil Ana Carolina Damboriarena Escosteguy, Pontifícia Universidade Católica do Rio Grande do Sul, Brasil

Ana Gruszynski, Universidade Federal do Rio Grande do Sul, Brasil Ana Silvia Lopes Davi Médola, Universidade Estadual Paulista, Brasi André Luiz Martins Lemos, Universidade Federal da Bahia, Brasil Ângela Freire Prysthon, Universidade Federal de Pernambuco, Brasil Angela Cristina Salgueiro Marques, Faculdade Cásper Líbero (São Paulo), Brasil Antônio Fausto Neto, Universidade do Vale do Rio dos Sinos, Brasil Antonio Carlos Hohlfeldt, Pontifícia Universidade Católica do Rio Grande do Sul, Brasil Antonio Roberto Chiachiri Filho, Faculdade Cásper Libero, Brasil Arlindo Ribeiro Machado, Universidade de São Paulo, Brasil Arthur Autran Franco de Sá Neto, Universidade Federal de São Carlos, Brasil Benjamim Picado, Universidade Federal Fluminense, Brasil César Geraldo Guimarães, Universidade Federal de Minas Gerais, Brasil Cristiane Freitas Guttreind, Pontifícia Universidade Católica do Rio Grande do Sul, Brasi Denilson Lopes, Universidade Federal do Rio de Janeiro, Brasil Denize Correa Araujo, Universidade Tuiuti do Paraná, Brasil Edilson Cazeloto, Universidade Paulista , Brasil Eduardo Peñuela Cañizal, Universidade Paulista, Brasi Eduardo Vicente, Universidade de São Paulo, Brasi Eneus Trindade, Universidade de São Paulo, Brasil Erick Felinto de Oliveira, Universidade do Estado do Rio de Janeiro, Brasil Florence Dravet, Universidade Católica de Brasília, Brasil Francisco Eduardo Menezes Martins, Universidade Tuiuti do Paraná, Brasi Gelson Santana, Universidade Anhembi/Morumbi, Brasil Gilson Vieira Monteiro, Universidade Federal do Amazonas, Brasi Gislene da Silva, Universidade Federal de Santa Catarina, Brasil Guillermo Orozco Gómez, Universidad de Guadalajara Gustavo Daudt Fischer, Universidade do Vale do Rio dos Sinos, Brasil Hector Ospina, Universidad de Manizales, Colômbia Herom Vargas, Universidade Municipal de São Caetano do Sul, Brasil leda Tucherman, Universidade Federal do Rio de Janeiro, Brasil Inês Vitorino, Universidade Federal do Ceará, Brasi Janice Caiafa, Universidade Federal do Rio de Janeiro, Brasil Jay David Bolter, Georgia Institute of Technology Jeder Silveira Janotti Junior, Universidade Federal de Pernambuco, Brasil João Freire Filho, Universidade Federal do Rio de Janeiro, Brasi
John DH Downing, University of Texas at Austin, Estados Unidos José Afonso da Silva Junior, Universidade Federal de Pernambuco, Brasil José Carlos Rodrigues, Pontifícia Universidade Católica do Rio de Janeiro, Brasil José Luiz Aidar Prado, Pontifícia Universidade Católica de São Paulo, Brasil José Luiz Warren Jardim Gomes Braga, Universidade do Vale do Rio dos Sinos, Brasil Juremir Machado da Silva, Pontifícia Universidade Católica do Rio Grande do Sul, Brasil Laan Mendes Barros, Universidade Metodista de São Paulo, Brasil Lance Strate, Fordham University, USA, Estados Unidos Lorraine Leu, University of Bristol, Grã-Bretanha Lucia Leão, Pontifícia Universidade Católica de São Paulo, Brasil Luciana Panke, Universidade Federal do Paraná, Brasil Luiz Claudio Martino, Universidade de Brasilia, Brasil Malena Segura Contrera, Universidade Paulista, Brasil Márcio de Vasconcellos Serelle, Pontifícia Universidade Católica de Minas Gerais, Brasil Maria Aparecida Baccega, Universidade de São Paulo e Escola Superior de Propaganda e Marketing, Brasil

Maria das Graças Pinto Coelho, Universidade Federal do Rio Grande do Norte, Brasil Maria Immacolata Vassallo de Lopes, Universidade de São Paulo, Brasil Maria Luiza Martins de Mendonça, Universidade Federal de Goiás, Brasil Mauro de Souza Ventura, Universidade Estadual Paulista, Brasil Mauro Pereira Porto, Tulane University, Estados Unidos Nilda Aparecida Jacks, Universidade Federal do Rio Grande do Sul, Brasi Paulo Roberto Gibaldi Vaz, Universidade Federal do Rio de Janeiro, Brasi Potiguara Mendes Silveira Jr, Universidade Federal de Juiz de Fora, Brasil Renato Cordeiro Gomes, Pontifícia Universidade Católica do Rio de Janeiro, Brasil Robert K Logan, University of Toronto, Canadá

Ronaldo George Helal, Universidade do Estado do Rio de Janeiro, Brasil Rosana de Lima Soares, Universidade de São Paulo, Brasil Rose Melo Rocha, Escola Superior de Propaganda e Marketing, Brasil Rossana Reguillo, Instituto de Estudos Superiores do Ocidente, Mexico Rousiley Celi Moreira Maia, Universidade Federal de Minas Gerais, Brasil Sebastião Carlos de Morais Squirra, Universidade Metodista de São Paulo, Brasi Sebastião Guilherme Albano da Costa, Universidade Federal do Rio Grande do Norte, Brasil

Simone Maria Andrade Pereira de Sá, Universidade Federal Fluminense, Brasil Tiago Quiroga Fausto Neto, Universidade de Brasília, Brasi Suzete Venturelli, Universidade de Brasília, Brasil Valério Cruz Brittos, Universidade do Vale do Rio dos Sinos, Brasil Valerio Fuenzalida Fernández, Puc-Chile, Chile Veneza Mayora Ronsini, Universidade Federal de Santa Maria, Brasil Vera Regina Veiga França, Universidade Federal de Minas Gerais, Brasil

\section{COMISSÃO EDITORIAL}

Adriana Braga I Pontifícia Universidade Católica do Rio de Janeiro, Brasil Felipe Costa Trotta I Universidade Federal de Pernambuco, Brasil

CONSULTORES AD HOC

Bárbara Heller, Universidade Paulista, Brasil

Luciana Mielniczuk, Universidade Federal do Rio Grande do Sul, Brasil Micael Herschmann, Universidade Federal do Rio de Janeiro, Brasil EDIČ̃̃ DE TEXTO E RESUMOS I Susane Barros SECRETÁRIA EXECUTIVA I Juliana Depiné EDITORAÇ̃o ELETRÔNICA I Roka Estúdio TRADUÇÃO I Sabrina Gledhill, Sieni Campos, Robert Finnegan
COMPós I www.compos.org.br

Associação Nacional dos Programas de Pós-Graduação em Comunicação

Presidente

Julio Pinto

Pontifícia Universidade Católica de Minas Gerais, Brasil

juliopinto@pucminas.br

Vice-presidente

Itania Maria Mota Gomes

Universidade Federal da Bahia, Brasil

itania@ufba.br

Secretária-Geral

Inês Vitorino

Universidade Federal do Ceará, Brasil

inesvict@gmail.com 